\title{
Detection of intracellular forms of secretory aspartic proteinase in Candida albicans
}

\author{
Michio Homma, ${ }^{*}$ Toshio Kanbe, HiRoji Chibana and Keni TaNaka \\ Laboratory of Medical Mycology, Research Institute for Disease Mechanism and Control, Nagoya University School of \\ Medicine, Showa-ku, Nagoya 466, Japan
}

(Received 30 July 1991; revised 11 October 1991; accepted 27 November 1991)

\begin{abstract}
The extracellular proteinase (EPR) of Candida albicans was induced in a medium containing bovine serum albumin as sole nitrogen source. There were two intracellular forms in cells induced to produce EPR, a 43 kDa protein (EPR) and a $45 \mathrm{kDa}$ protein (cross-reacting material of EPR; CRM-EPR); these were detected by immunoblotting using anti-EPR antiserum. The $43 \mathrm{kDa}$ protein (EPR) may be the same as the extracellular form judging by molecular mass, and the $45 \mathrm{kDa}$ protein (CRM-EPR) may be a precursor form of EPR. Many dense granules were observed by electron microscopy near the plasma membrane of the mother cells in EPR-producing cells. Both the 43 and $45 \mathrm{kDa}$ proteins were recovered in a membrane fraction and were solubilized by Triton X100. When the membrane fraction was further fractionated by sucrose density gradient centrifugation, the 43 and $45 \mathrm{kDa}$ proteins were differentially fractionated. This suggests that they were located in different membranebound structures and is consistent with an assumption that the $45 \mathrm{kDa}$ protein is a precursor for EPR.
\end{abstract}

\section{Introduction}

In common with many fungal species, Candida albicans, a medically important yeast and opportunistic pathogen, secretes a proteinase (for review see Odds, 1988). This secreted proteinase is thought to be a factor in virulence, a view supported by experiments on mice infected with proteinase-deficient strains (Kondoh et al., 1987; KwonChung et al., 1985; MacDonald \& Odds, 1983; Mori et al., 1989; Ross et al., 1990; Staib, 1969). However, the enzyme appears to act not as a virulence factor per se but rather assists propagation of the fungus in the host. The role of the proteinase is reported to include (i) assisting invasion by degradation of skin or mucosa (Borg \& Rüchel, 1988; Kaminishi et al., 1988; Kobayashi et al., 1989; Negi et al., 1984; Ray \& Payne, 1988; Shimizu et al., 1987), (ii) attacking antibodies, granulocytes and macrophages (Ghannoum \& Elteen, 1986; MacDonald \& Odds, 1983; Rüchel, 1984; Rüchel et al., 1986), and (iii) supplying nutrients by digestion of proteins (MacDonald, 1984; Shimizu et al., 1987).

*Author for correspondence. Tel. (052) 7412111 (ext. 2116); fax (052) 7319479.

\footnotetext{
Abbreviations: CBB, Coomassie brilliant blue; (CRM-) EPR, (crossreacting material of extracellular proteinase; ER, endoplasmic reticulum.
}

The extracellular proteinase (EPR) of $C$. albicans is an aspartic proteinase with a molecular mass of $43 \mathrm{kDa}$ (Remold et al., 1968; Shimizu et al., 1987). Enzyme production is induced in minimal media containing proteins as sole nitrogen source but not by low molecular mass nitrogen sources (Crandall \& Edwards, 1987; Ross et al., 1990; Shimizu et al., 1987). In addition, glucose stimulates its production (Samaranayake et al., 1984).

Studies on EPR have focussed on its virulence role without attention to the secretory pathway and intracellular forms have not been described. In this study, we examined some basic biological aspects of EPR in $C$. albicans. An assay system was developed to detect intracellular forms of the enzyme and its localization was investigated.

\section{Methods}

Strains. The strain of C. albicans used was C9 (Kwon-Chung et al., 1985) which had the highest EPR activity among our stock strains.

Media. YPD broth contained (per litre distilled water): polypeptone (Daigo), $10 \mathrm{~g}$; yeast extract (Daigo), $10 \mathrm{~g}$; and dextrose, $20 \mathrm{~g}$. YNB medium contained (per litre distilled water) yeast nitrogen base without amino acids and ammonium sulphate (Difco), $17 \mathrm{~g}$. EPR induction medium comprised $2 \%(\mathrm{w} / \mathrm{v})$ glucose and $0.2 \%$ BSA (Sigma) in YNB medium. A control medium in which EPR was not induced comprised EPR induction medium with $0.1 \mathrm{M}$-ammonium tartrate, which suppresses EPR production. 
Electrophoresis. SDS-PAGE was performed by the method of Laemmli (1970) using 10\% (w/v) polyacrylamide gels. Samples were prepared by mixing $0.05 \mathrm{ml}$ protein solution with $0.01 \mathrm{ml} 6 \times$ TDG buffer $(0.4 \mathrm{M}-\mathrm{Tris} / \mathrm{HCl}, \mathrm{pH} 6.8 ; 6 \%, \mathrm{w} / \mathrm{v}, \mathrm{SDS} ; 38 \%, \mathrm{v} / \mathrm{v}$, glycerol; $0.006 \%$ bromophenol blue) and $0.005 \mathrm{ml} 2$-mercaptoethanol. The sample solutions were heated at $100^{\circ} \mathrm{C}$ for $5 \mathrm{~min}$. The molecular mass markers used were BSA (68 kDa), ovalbumin (43 kDa), chymotrypsinogen $A(25 \mathrm{kDa})$ and ribonuclease $A(14 \mathrm{kDa})$.

Proteins in the gel were stained with $0.1 \%$ Coomassie brilliant blue R250 (CBB-R250) in methanol/acetic acid/water (5:1:4, by vol.) and destained in $7 \%(\mathrm{v} / \mathrm{v})$ acetic acid.

Preparation of anti-EPR serum. Purification of EPR was carried out as described by Shimizu et al. (1987). The purified EPR (1 mg) was run on an SDS-PAGE gel (to give a single band) to separate it from invisible contaminants. The gel was stained with $0.1 \%$ CBB-R250, washed with water, and the stained band was cut from the gel. The gel piece was blended in $0.9 \% \mathrm{NaCl}$ with a Teflon homogenizer. One-third of the homogenate was emulsified in Freund's complete adjuvant and injected intramuscularly into a rabbit. The same amount of a booster injection was given into the back 2 weeks later, and after an additional week, another booster of the remaining homogenate without adjuvant was injected into the back. The rabbit was bled 1 week after the third injection to obtain serum.

Immunoblotting. After components were separated by SDS-PAGE, the proteins or the other substances were transferred onto nitrocellulose sheets (Schleicher \& Schuell) or Immobilon sheets (Millipore) by the method of Howe \& Hershey (1985). Non-specific sites on the blotted sheets were blocked by incubating for $15 \mathrm{~min}$ at room temperature in $3 \%(\mathrm{w} / \mathrm{v})$ skimmed milk in TBS $(20 \mathrm{~mm}$-Tris/ $\mathrm{HCl}, \mathrm{pH} 7.8 ; 0.5 \mathrm{M}$ $\mathrm{NaCl})$. The blocked blots were immersed in specific antiserum diluted $1: 1000$ in $1 \%$ skimmed milk in TBS and incubated for $6 \mathrm{~h}$ or overnight with gentle shaking, and then washed in $1 \%$ skimmed milk in TBS four times ( 20 min each wash). The sheets were incubated with an affinitypurified anti-rabbit IgG antibody conjugated with horseradish peroxidase (HRP; Bio-Rad) or alkaline phosphates (AP; Promega) diluted $1: 2500$ in $1 \%$ skimmed milk in TBS for $5 \mathrm{~h}$, washing four times in $1 \%$ skimmed milk in TBS ( 5 min each wash), and adding the appropriate substrate. For HRP, the sheets were incubated in a mixture of $50 \mathrm{ml}$

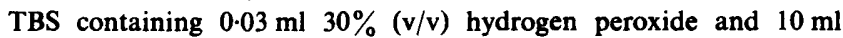
methanol containing $30 \mathrm{mg}$ 4-chloro-1-naphthol (Nakarai tesque Co.). For AP, the sheets were incubated in a mixture of $5 \mathrm{ml}$ AP buffer (100 mM-Tris/ $\mathrm{HCl}, \mathrm{pH} 9.5 ; 100 \mathrm{mM}-\mathrm{NaCl} ; 5 \mathrm{mM}-\mathrm{MgCl}_{2}$ ) containing $0.033 \mathrm{ml} \mathrm{NBT}$ solution (50 mg nitro blue tetrazolium $\mathrm{ml}^{-1}$ in $70 \%$ dimethylformamide) and $0.0165 \mathrm{ml} \mathrm{BCIP}$ solution (50 mg 5-bromo-4chloro-3-indolyl-phosphate $\mathrm{ml}^{-1}$ in dimethylformamide).

Induction of EPR. Cells were grown to exponential phase $\left(\mathrm{OD}_{660}\right.$ of about $1 \cdot 0)$ in YPD broth containing $1.1 \%(w / v)$ Casamino acids (Difco) with shaking at $37^{\circ} \mathrm{C}$, collected by centrifugation, resuspended in the original culture volume of EPR induction medium, and incubated with shaking at $37^{\circ} \mathrm{C}$. At various times, the cells were sedimented by centrifugation, and the resultant supernatant fluid and the pelleted cells (resuspended in $10 \mathrm{~mm}-\mathrm{NaN}_{3}$ to give an $\mathrm{OD}_{660}$ of 30) analysed by immunoblotting for extracellular and intracellular fractions, respectively.

Fractionation of EPR-producing cells. Cell fractionation was carried out by the method of Goud et al. (1988) with the following modifications. Strain $\mathrm{C} 9$ was grown to stationary phase in YPD broth with shaking at $37^{\circ} \mathrm{C}$. The culture was diluted 1:100 with EPR induction medium (21), allowed to grow to late exponential phase $\left(\mathrm{OD}_{660}\right.$ of about 1.5$)$ and the cells were pelleted by centrifugation. The cells were washed twice with cold $10 \mathrm{mM}-\mathrm{NaN}_{3}$, suspended in $40 \mathrm{ml}$ $50 \mathrm{mM}$-potassium phosphate buffer (pH 7.5) containing $1.4 \mathrm{M}$-sorbitol, and $20 \mathrm{mg}$ Zymolyase 100T (Seikagaku Kogyo) and 0.24 ml 2- mercaptoethanol were added to the suspension. After incubation at $37^{\circ} \mathrm{C}$ for $30 \mathrm{~min}$ without shaking, the resulting spheroplasts were collected by centrifugation at $10000 \mathrm{~g}$ for $20 \mathrm{~min}$, and suspended in $10 \mathrm{ml} 10 \mathrm{~mm}$-triethanolamine ( $\mathrm{pH} \mathrm{7.2)} \mathrm{containing} 0.8 \mathrm{M}$-sorbitol and 1 mM-EDTA. The suspension was homogenized by 20 strokes in a glass tissue grinder, and centrifuged at $10000 \mathrm{~g}$ for $20 \mathrm{~min}$ to sediment unbroken spheroplasts and cell debris. This breakage procedure was repeated three times and the pooled supernatant fluids were centrifuged at $10000 \mathrm{~g}$ for $20 \mathrm{~min}$. The resulting pooled supernatant fluids were centrifuged at $100000 \mathrm{~g}$ for $90 \mathrm{~min}$. The resulting supernatant fluid and pellet contained mainly cytoplasmic materials and membrane components, respectively. The pellet was suspended in $10 \mathrm{ml} 10 \mathrm{mM}$ triethanolamine containing $0.8 \mathrm{M}$-sorbitol and $1 \mathrm{mM}$-EDTA. A part of the suspension was layered on a $5-30 \%$ linear sucrose gradient in $10 \mathrm{~mm}$-triethanolamine ( $\mathrm{pH} \mathrm{7.2)}$ containing $0.8 \mathrm{M}$-sorbitol and $1 \mathrm{mM}$ EDTA, and centrifuged for $2 \mathrm{~h}$ at 25000 r.p.m. (Beckman SW41 rotor). The gradient was collected in $0.5 \mathrm{ml}$ fractions from the bottom of the tube.

Electron microscopy. To observe the ultrastructure of cells, freeze substitution electron microscopy was used as described previously (Tanaka \& Kanbe, 1986), except propane was used as the cryogen. Cells incubated in EPR induction or control medium were collected by centrifugation for $10 \mathrm{~min}$ at $1500 \mathrm{~g}$. A small amount of the cells was placed on copper grids by dipping the grids in the pellet, and immediately plunging the grids into liquid propane pre-cooled with liquid nitrogen to -180 to $-185^{\circ} \mathrm{C}$. The frozen samples were transferred to a substitution fluid of anhydrous acetone containing $2 \%$ $(\mathrm{w} / \mathrm{v}) \mathrm{OsO}_{4}$ and $0.05 \%$ uranyl acetate, maintained at $-79^{\circ} \mathrm{C}$ with dryice/acetone. After $48 \mathrm{~h}$, the samples were transferred to $-30^{\circ} \mathrm{C}$ for $3-$ $4 \mathrm{~h}$, then $4{ }^{\circ} \mathrm{C}$ for $1-1.5 \mathrm{~h}$, and finally to room temperature for $30 \mathrm{~min}$. They were rinsed four times with anhydrous acetone, embedded in Epon-Araldite, and polymerized at $60^{\circ} \mathrm{C}$ for $48 \mathrm{~h}$. Thin sections, obtained by use of a Reichert Ultracut OmU4 microtome equipped with a diamond knife, were stained with uranyl acetate and lead citrate. The sections were observed in a JEOL 100SX transmission electron microscope operating at $80 \mathrm{kV}$.

\section{Results}

\section{Detection of intracellular EPR}

Cells were grown to exponential phase in rich medium (YPD broth containing $1.1 \%$ Casamino acids) and transferred to EPR induction medium or control medium. After various incubation times, cells were harvested and proteins were solubilized by boiling in TDG buffer containing 2-mercaptoethanol for SDSPAGE. EPR was detected by immunoblotting using an anti-EPR antibody. Two distinct protein bands were detected in cells incubated in the induction medium (Fig. 1, lane 3) but not from pre-induced cells or control cells incubated in non-induction medium (Fig. 1, lanes 1 and 2). The bands were detected within a 15 min induction and the amount of enzyme appeared to increase with incubation time up to about $2 \mathrm{~h}$. The lower band had the same mobility as the band of $43 \mathrm{kDa}$ EPR which was purified from culture medium (Fig. 2). Based on the cross-reactivity against the anti-EPR antiserum and the molecular size, the intracellular $43 \mathrm{kDa}$ protein was 


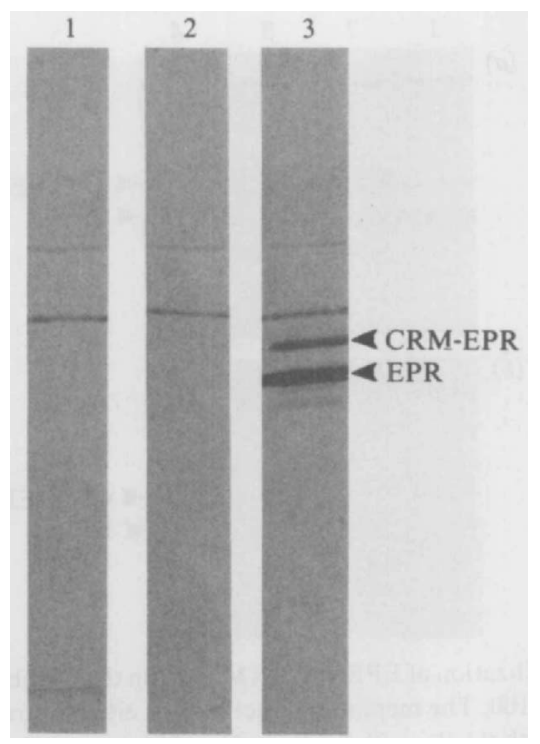

Fig. 1. Immunoblotting to detect intracellular EPR. Cells from an exponential-phase culture grown in YPD broth containing $1.1 \%$ Casamino acids (see Methods) were suspended in either EPR induction medium or control medium, then incubated at $37^{\circ} \mathrm{C}$ for $2 \mathrm{~h}$ with shaking. The cells and culture medium were separated by centrifugation in an Eppendorf centrifuge. The cells were suspended in $10 \mathrm{mM}$ $\mathrm{NaN}_{3}$ to give an $\mathrm{OD}_{660}$ of 30 . The cells were analysed by electrophoresis and immunoblotting was performed using anti-EPR antiserum. Lanes: 1, cells prior to EPR induction; 2, cells incubated in control medium; 3, cells in EPR induction medium. The arrowheads show the position of EPR (43 kDa) and of CRM-EPR (45 kDa).

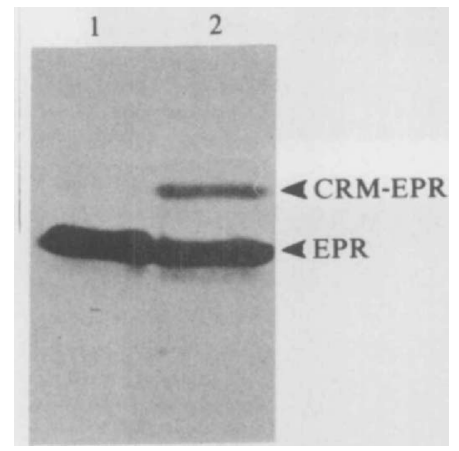

Fig. 2. Comparision of the extracellular and intracellular forms of EPR. After EPR was induced, as in Fig. 1, the culture medium (lane 1) and the cells (lane 2) were analysed by electrophoresis, and immunoblotting was performed using an affinity-purified anti-EPR antibody.

thought to be the same form as EPR. The upper band size estimated in an SDS-PAGE gel was $2 \mathrm{kDa}$ larger than EPR, and it was not detected in the culture medium (Fig. 2). We tentatively called it cross-reacting material of EPR (CRM-EPR). Two bands above the position of the CRM-EPR band, which were detected by using antiEPR serum, were also detected by preimmune serum (data not shown) and in the non-induced cells (Fig. 1,

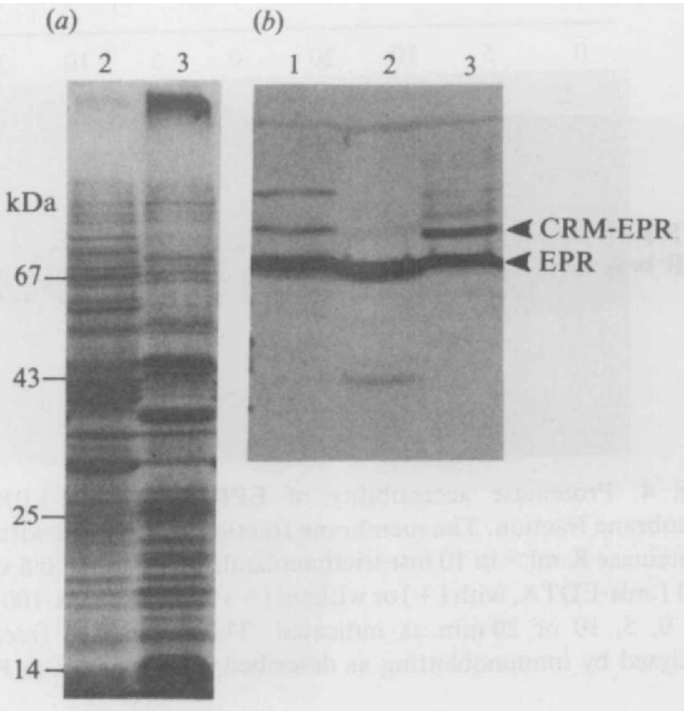

Fig. 3. Cellular location of EPR and CRM-EPR. The EPR-producing cells (lane 1) were fractionated into cytoplasmic (lane 2) and membrane (lane 3) fractions (see Methods), and proteins were analysed by electrophoresis followed by CBB-R250 staining (a) and immunoblotting using anti-EPR antiserum (b). Molecular mass markers are indicated.

lanes 1 and 2), but were not dectected by an affinitypurified antibody (Fig. 2). Thus the reactions of these two bands were not specific for anti-EPR antibody.

\section{Membrane-associated form of EPR and CRM-EPR}

Spheroplasts were lysed and fractionated into cytoplasmic and membrane fractions by differential centrifugation. Proteins were differentially detected between the two fractions by CBB-R250 staining (Fig. 3a). By immunoblotting of the SDS-PAGE gel, CRM-EPR was detected primarily in the membrane fraction, and EPR was found in both cytoplasmic and membrane fractions (Fig. $3 b$ ). In order to examine whether EPR and CRMEPR were actually associated with membranes, experiments were done as follows.

Proteinase accessibility of EPR and CRM-EPR in the membrane fraction was tested. The membrane fraction was incubated with Proteinase K. CRM-EPR was resistant to the proteinase in the absence of Triton X-100, but it was digested in the presence of Triton X-100 (Fig. 4). This shows that CRM-EPR is protected from proteinase $\mathrm{K}$ by a structure which is solubilized by Triton $X-100$. On the other hand, this treatment did not affect EPR. It seems that EPR by itself was resistant to added proteinases because purified extracellular EPR was not digested at all by either Proteinase $\mathrm{K}$ or trypsin (data not shown), and neither was the intracellular EPR digested by Proteinase K, with or without Triton X-100 (Fig. 4). It 


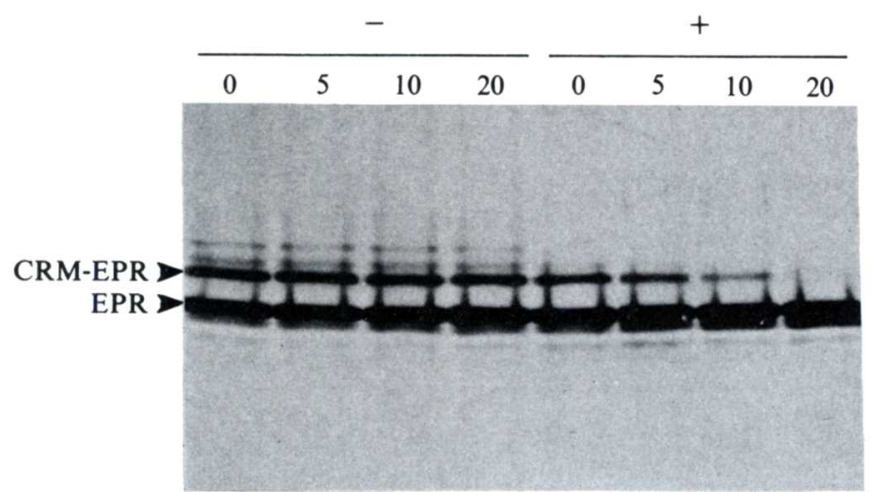

Fig. 4. Proteinase accessibility of EPR and CRM-EPR in the membrane fraction. The membrane fraction was treated with $0.05 \mathrm{mg}$ Proteinase $\mathrm{K} \mathrm{ml}^{-1}$ in $10 \mathrm{~mm}$-triethanolamine containing $0.8 \mathrm{M}$-sorbitol and 1 mM-EDTA, with (+) or without $(-) 0.5 \%$ Triton X-100, at $30^{\circ} \mathrm{C}$ for $0,5,10$ or $20 \mathrm{~min}$ as indicated. The membrane fraction was analysed by immunoblotting as described in the legend to Fig. 1.

is worth noting that the density of a band running just ahead of EPR was increased during the CRM-EPR digestion (Fig. 4). This indicates that CRM-EPR might be processed although it is not converted completely to EPR.

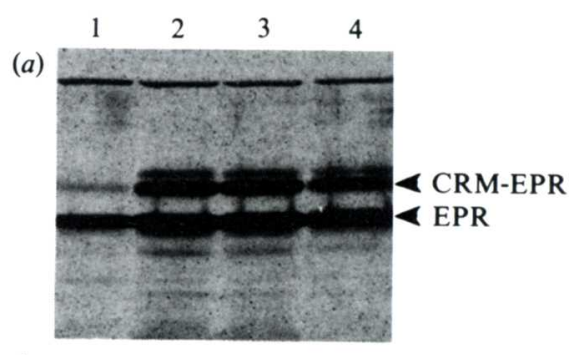

(b)

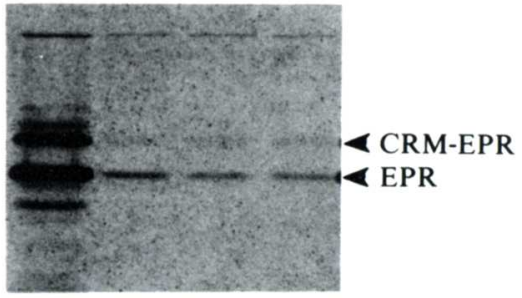

Fig. 5. Solubilization of EPR and CRM-EPR in the membrane fraction by Triton X-100. The membrane fraction was either untreated (lane 1) or treated with $0 \cdot 1$ (lane 2), 0.5 (lane 3) or $2 \%$ (lane 4 ) Triton X-100 in $10 \mathrm{mM}$-triethanolamine containing $0.8 \mathrm{M}$-sorbitol and $1 \mathrm{mM}$-EDTA at $30^{\circ} \mathrm{C}$. After $10 \mathrm{~min}$ incubation, the membrane fraction was centrifuged at $100000 \mathrm{~g}$ for $90 \mathrm{~min}$. Supernatant fluids $(a)$ and the pellets suspended in the original volume of buffer $(b)$ were analysed by immunoblotting as described in the legend to Fig. 1.

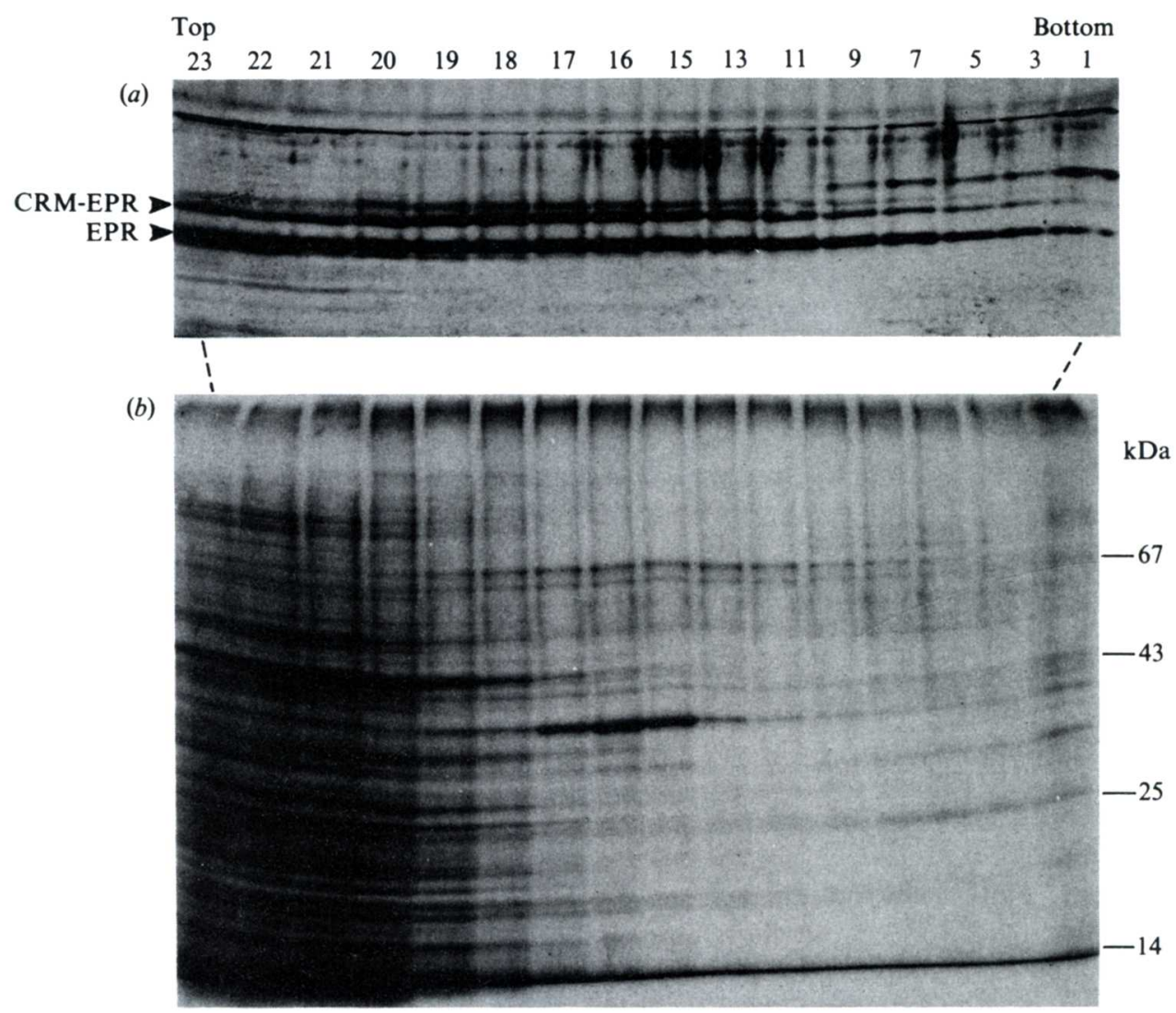

Fig. 6. Sucrose density gradient centrifugation of the membrane fraction. The membrane fraction was further fractionated in a 5-30\% linear sucrose gradient. The gradient was collected from the bottom of the tube in 23 fractions. The fractions were analysed by electrophoresis followed by immunoblotting using anti-EPR antiserum (a) and CBB-R250 staining (b). The fraction number analysed is indicated above the lanes. Molecular mass markers are indicated. 

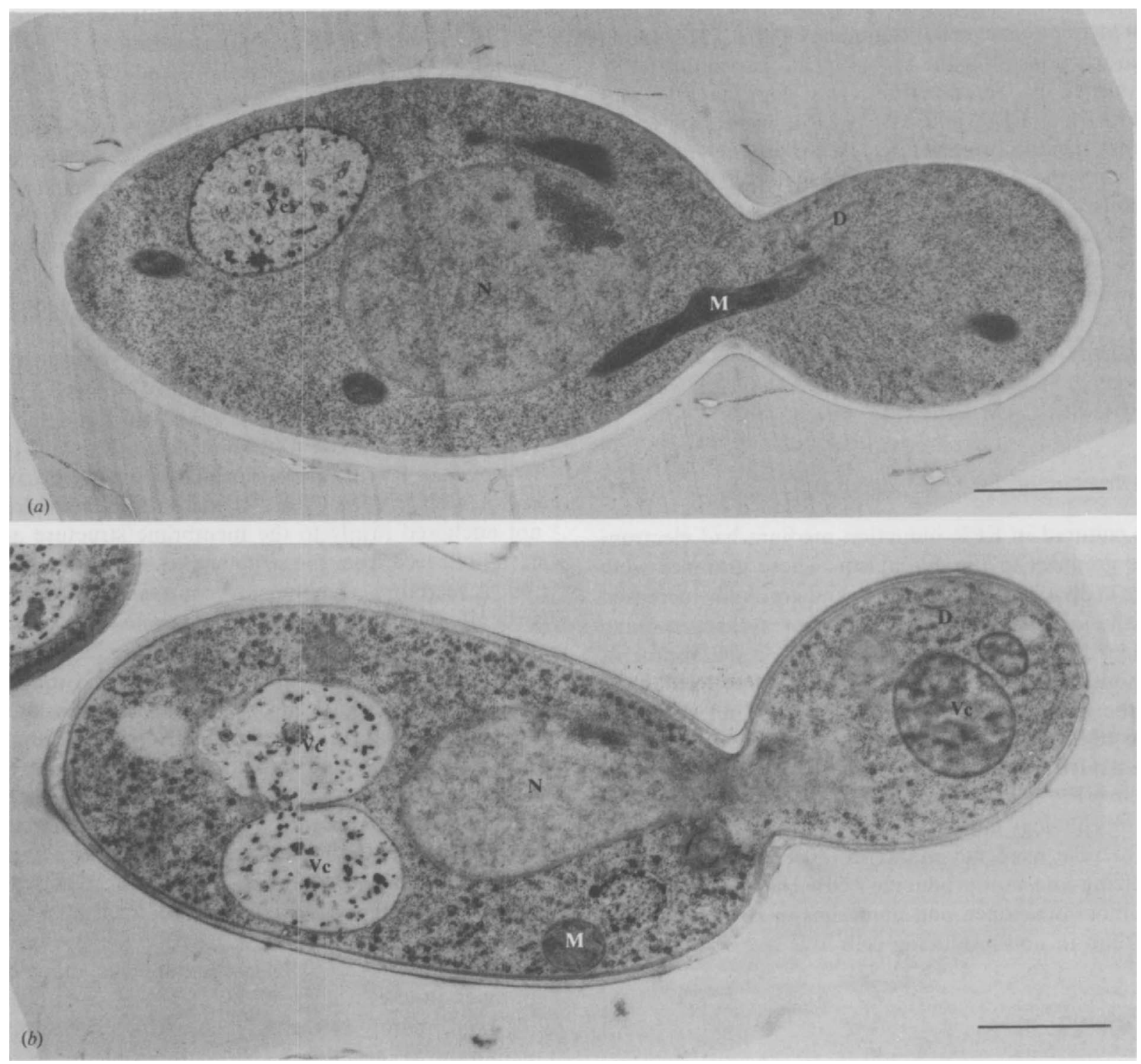

Fig. 7. Electron micrographs of EPR-induced and non-induced cells. Cells from an exponential-phase culture were suspended in EPR non-induction medium $(a)$ and EPR induction medium $(b)$. After $2 \mathrm{~h}$ incubation, the cells were fixed by freezing. The sample was prepared for electron microscopy as described in Methods. D, dictyosome; M, mitochondrion; N, nucleus; Vc, vacuole. Bars, $1 \mu \mathrm{m}$.

The membrane fraction was treated with Triton $\mathrm{X}$ 100 , and centrifuged at high speed (Fig. 5). At $0.1 \%$ Triton X-100, EPR and CRM-EPR were almost absent from the pellet, but appeared in the supernatant fluid. It is probable that the membrane structure was solubilized by Triton X-100 and that EPR and CRM-EPR associated with the membrane were also solubilized. About onethird of the EPR was detected in the supernatant fluid even in the control without Triton X-100. This would be explained if EPR were not anchored to the membrane structure but was released as a result of mechanical damage to membranes or vesicles when the membrane fraction pellet was suspended in the buffer. A band running just above CRM-EPR was detected immunologically in the concentrated membrane fraction. This might be a prepro form of EPR, or a modified form of CRM-EPR or EPR.

\section{Membrane fractionation}

The membrane fraction was further fractionated by sucrose density gradient centrifugation (Fig. 6). The majority of proteins remained in the top fractions (Fig. $6 b$, fractions 20-23). Fractions 22 and 16 were estimated to contain the highest amounts of EPR by the band densities though EPR was detected in all fractions (Fig. 
$6 a$ ). Fractions 17 and 18 contained the greatest amount of CRM-EPR. The peak fraction of CRM-EPR was one or two fractions after the second peak fraction of EPR. This order of fractionation was reproducible and suggests that EPR and CRM-EPR were located in different membrane structures. A fairly large amount of EPR with the first peak was also detected in the top fractions. EPR in the top fractions seems to correspond to EPR released from membrane structures (see above).

Several proteins detected by CBB-R250 staining were co-purified with EPR or CRM-EPR and they might reside in the same membrane structures (Fig. 6b). It is noteworthy that a protein, detected by anti-EPR antibody which ran just above CRM-EPR, was copurified with CRM-EPR (Fig. 6a).

\section{Ultrastructure of the EPR-induced cell}

Cells cultured in EPR induction medium had electrondense granules in the cytoplasm. These granules were scarce at $30 \mathrm{~min}$ after induction, and gradually increased with the incubation time. At $2 \mathrm{~h}$ after induction, many granules were observed near the plasma membrane of the mother cells but fewer in daughter cells (Fig. 7b). At $4 \mathrm{~h}$, the granules were observed throughout the cytoplasm (data not shown). There were few granules but these tended to increase in number with the incubation time in EPR non-producing cells (Fig. 7a). Ultrastructural morphology of dictyosome, mitochondrion, nucleus and vacuole were not markedly different between the producing and non-producing cells. However, vacuoles were more developed and numerous in EPR-producing cells than in non-producing cells.

\section{Discussion}

C. albicans is able to grow in a medium which contains as sole nitrogen source a protein which is digested by EPR. We developed an EPR induction system which yielded EPR within $1 \mathrm{~h}$ of induction. Cells were grown to exponential phase in a rich medium containing Casamino acids which repressed EPR production, then transferred to an EPR induction medium. Two intracellular proteins of 43 and $45 \mathrm{kDa}$ were detected immunologically in EPR-producing cells but not in control cells (Fig. 1). The $43 \mathrm{kDa}$ protein is thought to be the same form as the extracellular EPR based on its molecular size. The $45 \mathrm{kDa}$ protein, called CRM-EPR, which was not detected in culture medium (Fig. 2), is thought to be a precursor form of EPR (discussed below).

The cellular locations were estimated by a crude fractionation using ultracentrifugation giving cytoplasmic and membrane fractions. From the following three lines of evidence, EPR and CRM-EPR were deduced to be located in a membrane-bound structure or vesicle in the membrane fraction. First, EPR and CRM-EPR were recovered in a membrane fraction separated by ultracentrifugation (Fig. 3). Second, CRM-EPR was resistant to proteinases but digested in the presence of Triton X-100 which solubilizes membranes (Fig. 4). The effect of the detergent on EPR could not be examined because EPR was resistant to the proteinase. Third, when the membrane fraction was treated with Triton X-100, neither EPR nor CRM-EPR were sedimented by ultracentrifugation (Fig. 5).

During fractionation, EPR was detected in the cytoplasmic as well as the membrane fractions (Fig. $3 b$ ) and EPR in the membrane fraction was not completely sedimented again even without Triton X-100 (Fig. 5). However, CRM-EPR was primarily recovered in the sedimented fraction. The evidence suggests that EPR is not anchored firmly to the membrane structure and is easily released from the structure, as would be expected for a secretory enzyme. In contrast, CRM-EPR is strongly associated with the membrane structures.

In the well-established pathway for secreted proteins (Burgess \& Kelly, 1987), newly synthesized mRNA is transferred from nuclei to cytoplasm and translated on the rough endoplasmic reticulum (ER). The synthesized proteins are delivered into the ER lumen, then transferred by transport vesicles to the Golgi apparatus, where they are sorted into secretory vesicles. The vesicles are transported to the plasma membrane, fuse with the membrane, and the enclosed proteins are released into the extracellular space. If EPR is secreted by a similar pathway, intracellular EPR should be sorted into secretory vesicles. In EPR-producing cells, many dense granules in the size range of secretory vesicles, were observed, mainly in the cytoplasm close to the plasma membrane (Fig. 7). Vesicles in the general secretory pathway, which probably carry cell wall components and enzymes in the growing cell, are usually observed in budding sites (Baba et al., 1989; Schekman \& Novick, 1982). It would be interesting to determine whether the dense granules are secretory vesicles containing EPR, a question we are trying to answer using immunoelectron microscopy.

From the following lines of information it is likely that CRM-EPR is a precursor form of EPR in the secretory pathway. Lytic enzymes such as proteinases are normally produced as inactive precursors and are activated only at their final destination (Hasilik \& Tanner, 1978; Mechler et al., 1982). Many secretory proteins are produced as a precursor form containing a signal peptide or a sorting signal peptide (Verner \& Schatz, 1988) and the amino acid sequence of EPR deduced from its DNA sequence suggests that it is produced in this way (Hube et al., 
1991). Thus, the membrane structure harbouring CRMEPR may be the Golgi or ER membranes which precede the secretory vesicles in the secretory pathway. This assumption is consistent with our result that EPR and CRM-EPR seem to be present in different membrane structures because they were not co-purified by sucrose density gradient centrifugation (Fig. 6).

We thank J. E. Cutler (Montana State University, USA) for critically reading the manuscript. This work was supported (M.H.) by the Nitto foundation.

\section{References}

Baba, M., Baba, N., OHsumi, Y., Kanaya, K. \& Osumi, M. (1989). Three-dimensional analysis of morphogenesis induced by mating pheromone alpha factor in Saccharomyces cerevisiae. Journal of Cell Science 94, 207-216.

BORG, M. \& RüchEL, R. (1988). Expression of extracellular acid proteinase by proteolytic Candida spp. during experimental infection of oral mucosa. Infection and Immunity 56, 628-631.

Burgess, T. L. \& Kelly, R. B. (1987). Constitutive and regulated secretion of proteins. Annual Review of Cell Biology 3, 243-249.

Crandall, M. \& EdWardS, J. E. (1987). Segregation of proteinasenegative mutants from heterozygous Candida albicans. Journal of General Microbiology 133, 2817-2824.

Ghannoum, M. \& Elteen, K. A. (1986). Correlative relationship between proteinase production, adherence and pathogenicity of various strains of Candida albicans. Journal of Medical and Veterinary Mycology 24, 407-413.

Goud, B., Salminen, A., Walworth, N. C. \& Novick, P. J. (1988). A GTP-binding protein required for secretion rapidly associates with secretory vesicles and the plasma membrane in yeast. Cell 53, 753768.

HASILIK, A. \& TANNER, W. (1978). Biosynthesis of the vacuolar yeast glycoprotein carboxypeptidase Y. European Journal of Biochemistry $85,559-608$.

HowE, J. G. \& Hershey, W. B. (1985). A sensitive immunoblotting method for measuring protein synthesis initiation factor levels in lysates of Escherichia coli. Journal of Biological Chemistry 256, 1283612839.

Hube, B., Turver, C. J., Odds, F. C., Eiffert, H., Boulnois, G. J., KOCHEL, H. \& RüCHEL, R. (1991). Sequence of the Candida albicans gene encoding the secretory aspartate proteinase. Journal of Medical and Veterinary Mycology 29, 129-132.

Kaminishi, H., Hagihara, Y., Tanaka, M. \& Cho, T. (1988). Degradation of bovine achilles tendon collagen by Candida albicans proteinase. Journal of Medical and Veterinary Mycology 26, 315-318.

Kobayashi, I., Kondoh, Y., Shimizu, K. \& Tanaka, K. (1989). A role of secreted proteinase of Candida albicans for the invasion of chick chorio-allantoic membrane. Microbiology and Immunology 33, 709719.

Kondoh, Y., Shimizu, K. \& Tanaka, K. (1987). Proteinase production and pathogenicity of Candida albicans. Microbiology and Immunology 31, 1061-1069.
Kwon-Chung, K. J., Lehman, D., Good, C. \& Magee, P. T. (1985). Genetic evidence for role of extracellular proteinase in virulence of Candida albicans. Infection and Immunity 49, 571-575.

LAEMMLI, U. K. (1970). Cleavage of structural proteins during the assembly of the head of bacteriophage T4. Nature, London 227, 680685.

MacDonald, F. (1984). Secretion of inducible proteinase by pathogenic Candida species. Journal of Medical and Veterinary Mycology 22, 79-82.

MacDonald, F. \& OdDS, F. C. (1983). Virulence for mice of a proteinase secreting strain of Candida albicans and a proteinasedeficient mutant. Journal of General Microbiology 129, 431-438.

MeCHLER, B., MULLER, M., MULLER, H. \& WOLF, D. H. (1982). In vivo biosynthesis of the vacuolar proteinases $A$ and $B$ in the yeast Saccharomyces cerevisiae. Journal of Biological Chemistry 257, 1120311206.

Mori, R., Kobayashi, I., Shimizu, K., Kondoh, Y. \& Tanaka, K. (1989). Pathogenicity of Candida albicans strain with different proteinase activity in the rabbit cornea. Japanese Journal of Medical Mycology 30, 153-159.

Negi, M., Tsuboi, R., Matsui, T. \& Ogawa, H. (1984). Isolation and characterization of proteinase from Candida albicans: substrate specificity. Journal of Investigative Dermatology 83, 32-36.

ODDS, F. C. (1988). Pathogenesis of Candidosis. In Candida and Candidosis; a Review and Bibliography, pp. 253-278. London: Bailliere Tindall.

RAY, T. L. \& PAYNE, C. D. (1988). Scanning electron microscopy of epidermal adherence and cavitation in murine candidiasis: a role for Candida acid proteinase. Infection and Immunity 56, 1942-1949.

Remold, H., Fasolk, H. \& Staib, F. (1968). Purification and characterization of a proteolytic enzyme from Candida albicans. Biochimica et Biophysica Acta 167, 399-406.

Ross, I. K., De Bernardis, F., Emerson, G. W., Cassone, A. \& Sullivan, P. A. (1990). The secreted aspartate proteinase of Candida albicans: physiology of secretion and virulence of a proteinasedeficient mutant. Journal of General Microbiology 136, 687-694.

RüCHEL, R. (1984). A variety of Candida proteinases and their possible targets of proteolytic attack in the host. Zentralblatt für Bakteriologie, Mikrobiologie und Hygiene A257, 266-274.

RÜCHEL, R., BONING, B. \& BORG, M. (1986). Characterization of a secretory proteinase of Candida parapsilosis and evidence for the absence of the enzyme during infection in vitro. Infection and Immunity 53, 411-419.

Samaranayake, L. P., Hughes, A. \& Macfarlane, T. W. (1984). The proteolytic potential of Candida albicans in human saliva supplemented with glucose. Journal of Medical Microbiology 17, 13-22.

Schekman, R. \& Novick, P. (1982). The secretory process and yeast cell-surface assembly. In Molecular Biology of the Yeast Saccharomyces: Metabolism and Gene Expression, pp. 361-393. Edited by J. N. Strathern, E. W. Jones \& J. R. Broach. Cold Spring Harbor, NY: Cold Spring Harbor Laboratory.

ShimizU, K., Kondoh, Y. \& TANAKA, K. (1987). Proteinase production and pathogenicity of Candida albicans. Microbiology and Immunology 31, 1045-1060.

StaIB, F. (1969). Proteolysis and pathogenicity of Candida albicans strains. Mycopathologia 37, 345-348.

Tanaka, K. \& Kanbe, T. (1986). Mitosis in the fission yeast Schizosaccharomyces pombe as revealed by freeze-substitution electron microscopy. Journal of Cell Science 80, 253-268.

Verner, K. \& Schutz, G. (1988). Protein translocation across membranes. Science 241, 1307-1313. 